\title{
ANÁLISIS
}

\section{El modelo chino: un país, seis autores ${ }^{*}$}

DOI: $10.32870 /$ mycp.v14i40.359

Minglu Chen ${ }^{1}$

David S. G. Goodman ${ }^{2}$

\section{Introducción}

$\mathrm{E}$

1 rápido desarrollo económico de la República Popular China no sólo

ha sido espectacular desde 1978, sino que además sugiere que en

China existe un modelo específico de relaciones entre la sociedad, el Estado y el mercado. En concreto, la aplicación de este modelo podría resultar especialmente útil en las economías menos desarrolladas del mundo. Es obvio que la aparición de un Consenso de Pekín para sustituir al Consenso de Washington de los años noventa, capitalista y democrático, parece sugerir que el ascenso de China le ha permitido conseguir el apoyo de muchas regiones del mundo. El análisis de seis destacadas explicaciones distintas acerca de la creciente importancia política y económica de China sugiere que existen límites claros en la conceptualización del desarrollo de China como modelo, aunque es posible que podamos aprender otras cosas en un plano más general. Aun así, es probable que lo que aprendamos tenga una aplicación limitada en Latinoamérica.

El "modelo chino" es la expresión que ahora suele utilizarse, o a la que se alude, para describir el sustancial y sostenido desarrollo y crecimiento económico de la República Popular China (RPC) desde finales de 1978, y las

\footnotetext{
* Artículo recibido el 08 de noviembre de 2010 y dictaminado el 07 de diciembre de 2010.

1. Investigadora del Consejo Australiano de Investigación del Departamento de Gobierno y Re-laciones Internacionales de la Universidad de Sidney. ORCID http:// orcid.org/0000-0003-1710-4773

2. Profesor-investigador łeUniversidad de Sidney. ORCID http:// orcid.org/0000-0003-4965-6177
} 
consecuencias políticas de ese crecimiento y desarrollo. ${ }^{3}$ Este modelo chino, en su contexto internacional, también se denomina a veces Consenso de Pekín, en contraste con el anterior Consenso de Washington, basado en el capitalismo democrático y en políticas de desarrollo claramente neoliberales, que dominó en los años noventa. ${ }^{4}$ Sea cual sea la etiqueta descriptiva que se utilice, se suele asumir no sólo que la RPC

No se ha llegado a un

acuerdo sobre las principales

características del desarrollo

de China en las últimas

tres décadas, sobre si es

reproducible o sobre el mismo

hecho de si es deseable

aprender de China ha aplicado una receta específica para desarrollarse, sino también que otros países podrían copiar su modelo o, al menos, aprender de su experiencia.

El problema a la hora de realizar el análisis de esta situación consiste en que no se ha llegado a un acuerdo sobre las principales características del desarrollo de China en las últimas tres décadas, sobre si es reproducible o sobre el mismo hecho de si es deseable

aprender de China. Existe acuerdo en que se ha realizado una reforma económica, pero no sobre la naturaleza de dicha reforma, especialmente en lo referente a los papeles desempeñados por el Estado y la empresa privada en el desarrollo económico. Es más, mientras que algunos estudiosos contrastan la reforma económica con una ausencia de cambio político, otros argumentan que la reforma política también ha sido fundamental para conseguir los éxitos de las últimas tres décadas. Sobre la cuestión de si existe en realidad un modelo (un plan de desarrollo de algún tipo que otros puedan imitar), el

3. Se ha escrito mucho sobre este tema. Dos excelentes puntos de partida son Randall Peerenboom, China Modernizes: Threat to the West or Model for the Rest? Nueva York: Oxford University Press, 2008; y Suisheng Zhao, "The China Model: Can it replace the Western model of modernization?", Journal of Contemporary China, vol. 19, núm. 65, junio 2010, pp. 419-436. Véase también David S. G. Goodman, "El modelo chino de desarrollo: Reforma, no revolución", en Melba E. Falck Reyes y Roberto Hernández Hernández (ed.), El modelo de desarrollo asiático: Relevancia para México. Publicaciones de la Universidad de Guadalajara, 2004, pp. 111-140.

4. La idea del Consenso de Pekín se desarrolló por primera vez en un folleto de Joshua Cooper Ramo, The Beijing Consensus. Londres: The Foreign Policy Centre, mayo 2004. Su formulación más reciente se encuentra en Stefan Halper, The Beijing Consensus: How China's Authoritarian Model will Dominate the Twenty-First Century. Nueva York: Basic Books, 2010. 
creador del término Consenso de Pekín afirma de manera bastante explícita que "por supuesto, el camino hacia el desarrollo y el poder que ha seguido China no puede recorrerlo ninguna otra nación", aunque hace hincapié en la importancia del "efecto imitación" y de la influencia de China en gran parte del mundo. ${ }^{5}$

Latinoamérica ocupa desde hace mucho tiempo un papel central en los debates sobre la modernización de los países menos desarrollados. De hecho, muchos modelos de modernización y desarrollo creados por analistas o utilizados por quienes implementan dichos modelos proceden de Latinoamérica o se aplican a ella. Estos modelos incluyen una variada gama de conceptos y enfoques, desde los relacionados con modelos de sustitución de importaciones hasta las ideas de colonialismo interno, pasando por la democratización y, especialmente, el capitalismo democrático. ${ }^{6}$ La propia noción de la existencia de un Consenso de Washington que, se dice ahora, ha sido o será sustituido por el Consenso de Pekín como modelo de desarrollo, nació a finales de los años ochenta y a principios de los noventa como suma de la experiencia latinoamericana y el capitalismo democrático liberal. ${ }^{7}$ Como se afirma en un reciente informe:

La historia del desarrollo social y económico en Latinoamérica está dominada por la búsqueda de nuevos paradigmas: formas simplificadas de comprender el funcionamiento de la economía y la sociedad. Latinoamérica ha adoptado sucesivos paradigmas, desde el desarrollo introspectivo y patrocinado por el Estado de la posguerra, hasta la disciplina macroeconómica y la liberalización del comercio que postulaba el Consenso de Washington en los años noventa. Como sucedió con otros paradigmas, el entusiasmo de la región por el Consenso

5. Joshua Cooper Ramo, The Beijing Consensus. Londres: The Foreign Policy Centre, mayo 2004, p. 5.

6. Eliana Cardoso y Ann Helwege, Latin America's Economy: Diversity, Trends, and Conflicts. MIT Press, 1995; Andre Gunder Frank, The development of underdevelopment. Nueva York: BobbsMerrill, 1969; Andre Gunder Frank, Capitalism and Underdevelopment in Latin America: Historical Studies of Chile and Brazil. Nueva York: Monthly Review Press, 1969; Mabel Morana, Enrique Dussel, y Carlos A. Jáuregui (eds.), Coloniality at Large: Latin America and the Postcolonial Debate. Duke University Press, 2008; Frances Hagopian y Scott P. Mainwaring (eds.), The Third Wave of Democratization in Latin America: Advances and Setbacks. Cambridge University Press, 2005; Scott Mainwaring y Timothy Scully (eds.), Democratic Governance in Latin America. Stanford University Press, 2009.

7. John Williamson, "What Washington Means by Policy Reform", Latin American Adjustment: How Much Has Happened? Washington D. C.: Institute for International Economics, abril 1990. 
de Washington ha disminuido, y ahora busca un nuevo paradigma que ofrezca mejores resultados económicos, más estabilidad y un mayor nivel de equidad". ${ }^{8}$

La interacción de China con la teoría de la modernización es bastante distinta. Durante los años cincuenta, y especialmente durante el "gran salto adelante" (1958-1960), la RPC se consideraba un modelo particular y eficaz de socialismo de Estado. ${ }^{9}$ Durante la "revolución cultural" (1966-1976) muchos analistas occidentales, entre quienes se incluían economistas, alabaron su modelo de desarrollo, y en especial el hecho de fomentar un estilo de vida socialista junto con el crecimiento económico. ${ }^{10} \mathrm{El}$ rechazo del Partido Comunista de China de la política de la revolución cultural, y su adopción de un programa diseñado para conseguir un rápido crecimiento económico a finales de 1978 han marcado el comienzo de una nueva era en el cuestionamiento chino de las ideas de modernización. ${ }^{11}$

En muchos sentidos, el crecimiento económico de la RPC desde 1978 parece cuestionar directamente las teorías del desarrollo económico. La principal crítica a las teorías de la modernización, tal como se entendían anteriormente, es que la experiencia de la RPC parece sugerir que la política autoritaria y la reestructuración económica pueden coexistir. Desde luego, en muchos sentidos, desde 1978 la característica más destacada del desarrollo de la RPC parece haber sido no sólo la continuidad del poder del Partido Comunista Chino (PCC), sino su capacidad de adaptación. ${ }^{12}$ Esto ha llevado incluso a algunos analistas a mantener que el centralismo democrático de China no sólo

8. Banco Interamericano de Desarrollo, The Politics of Policies: Report on Economic and Social Progress in Latin America. Washington: Banco Interamericano de Desarrollo; y Cambridge (Massachusetts): David Rockefeller Center for Latin American Studies, 2006, p. 3.

9. Véase, por ejemplo, Isobel y David Crook, First Years of the Yangyi Commune. Londres: Routledge, 1966.

10. Joan Robinson, The Cultural Revolution in China. Harmondsworth (Middlesex): Penguin, 1972; Mark Selden y Victor D. Lippit (eds.), Transition to Socialism in China. Nueva York: M. E. Sharpe, 1982.

11. Se ha escrito largo y tendido sobre este tema. El mejor volumen sobre el cambio estratégico que se produjo, y su política, es el estudio de Solinger sobre las nuevas prioridades industriales. Dorothy J. Solinger, From Lathes to Looms: China's Industrial Policy in Comparative Perspective, 1979-1982. Stanford University Press, 1991.

12. David Shambaugh, China's Communist Party: Atrophy and Adaptation. University of California Press, 2009. 
es "decente", sino que es al menos igual de bueno que la democracia liberal como sistema de gobierno. ${ }^{13}$

El cuestionamiento de los conceptos generalmente aceptados acompaña a la consideración de gran parte del desarrollo económico de la RPC. Una tasa de crecimiento económico de $9-10 \%$ anual durante 30 años, con poca o ninguna hiperinflación, habría parecido poco probable hace 30 años. De hecho, cuando en 1978 se anunció por primera vez el objetivo de duplicar y reduplicar el PIB de la RPC para el año 2000, los economistas especializados en el análisis de la economía china acogieron la noticia con enorme escepticismo (con excepción de los economistas de la propia RPC). Se consideró una aspiración deseable, pero inalcanzable. ${ }^{14}$ Este objetivo se alcanzó en 1995. Gran parte del desarrollo posterior de la economía se ha caracterizado por un patrón de desarrollo y reacción escéptica, tanto a nivel macro como microeconómico. Durante los últimos 10 años, por ejemplo, han llegado advertencias del exterior sobre la burbuja inmobiliaria, que estaba a punto de estallar. ${ }^{15} \mathrm{El} \mathrm{reciente} \mathrm{paquete} \mathrm{de}$ medidas de estímulo de la RPC y sus intentos por evitar la posible influencia negativa de la crisis financiera global, especialmente a través del desarrollo de una red ferroviaria de alta velocidad, han sido recibidos con no poco desdén por los analistas externos. ${ }^{16} \mathrm{Y}$, a pesar de ello, no han fracasado, y ni siquiera se ha producido un paréntesis en el desarrollo, aunque siempre se corre el peligro de pecar de orgulloso con una afirmación de este tipo.

Tanto el éxito del crecimiento económico como el evidente cuestionamiento de los conceptos generalmente aceptados sobre desarrollo económico hacen posible que China ofrezca una ruta diferente hacia la modernización. En esto consiste básicamente el origen intelectual de la búsqueda de un modelo chino. Se trata de una poderosa metáfora, especialmente teniendo en cuenta los problemas de desarrollo económico de la primera década del siglo XXI. Como dijo Ramo, incluso antes de la crisis financiera global de 2008:

13. Stephen C. Angle, "Decent Democratic Centralism", Political Theory, vol. 33, núm. 4, agosto 2005, pp. 518-546.

14. Véase en The China Quarterly Chronicle and Documentation, marzo 1979.

15. Véase, por ejemplo, David Pierson, "In China real estate fever is rising", Los Angeles Times, 26 de abril de 2010.

16. Véase, por ejemplo, "Stealing the Airlines' Business", en Economist, 12 de febrero de 2010; "High-speed rail on fast track to nowhere", South China Morning Post, 6 de julio de 2010; South China Morning Post, 6 de julio de 2010; "China: a future on track", Financial Times, 28 de septiembre de 2010 . 
[...] el Consenso de Pekín es una esperanza para el mundo. Tras el fracaso del Consenso de Washington, la interrupción de las conversaciones de la OMC y la implosión de la economía de Argentina, gran parte del mundo no sabía cómo debería ser el nuevo paradigma del desarrollo. ${ }^{17}$

El problema se presenta al intentar desarrollar más esta idea básica. Es obvio que el rápido desarrollo económico de China ha generado mucha riqueza a nivel global. Al mismo tiempo, como bien atestigua el desarrollo de Latinoamérica, este crecimiento ha obligado al resto del mundo a adaptarse al ascenso de China. Pero, a un nivel más profundo, la idea del desarrollo de China también cuestiona las nociones de modernización y desarrollo económico. El grado de apoyo obtenido por el modelo chino se debe a que la experiencia de China se considera una ruta alternativa que otros podrían seguir, y no simplemente una ruta sui generis. El examen de los argumentos esgrimidos por seis autores (Joshua Cooper Ramo, Giovanni Arrighi, Martin Jacques, Stefan Halper, Suisheng Zhao y Barry Naughton) en publicaciones recientes sugiere que existen muy pocas pruebas de que el modelo chino sea reproducible en ese sentido. El desarrollo de la RPC desde 1978 es más bien resultado de unas circunstancias únicas, aunque por supuesto los demás pueden aprender de esta experiencia, siempre teniendo en cuenta que determinadas prácticas y procesos tienen ventajas, pero también inconvenientes.

\section{La búsqueda del consenso}

La idea de que podría existir un modelo chino es muy atrayente. La RPC ha tenido espectaculares tasas de crecimiento económico durante 30 años, y ha transformado el país. Las Olimpiadas de Pekín y la Expo de Shangai, por no mencionar las universidades de nivel nacional, han demostrado no sólo que China ha alcanzado un nivel de riqueza y competencia técnica cada vez más equiparable al de los países más desarrollados del mundo, sino también que es posible que un país poco desarrollado se convierta en uno de los más ricos. La economía china es ahora la segunda más importante del mundo, y prácticamente la mitad de los países (México y Canadá son importantes excepciones) tienen a la RPC como principal socio comercial.

17. Joshua Cooper Ramo, The Beijing Consensus. Londres: The Foreign Policy Centre, mayo 2004, p. 60. 
Por supuesto, este cuadro de éxitos no está completo. Siguen existiendo bolsas de la más terrible pobreza en China, y la desigualdad ha aumentado significativamente. La renta media anual disponible por habitante en las zonas rurales sigue siendo de sólo 3,587 yuanes, mientras que la media en las zonas urbanas llega a los 11,759 yuanes. A pesar de su limitada validez como indicador de desigualdad, el coeficiente de Gini en China ha pasado de 0.22 en 1978 a 0.49 en $2009 .{ }^{18}$ A pesar de ello, no pasa inadvertido ni al observador más desatento que la RPC se ha convertido en el taller del mundo, que las posibilidades de que continúe el crecimiento son importantes y que la generación de riqueza ha supuesto beneficios individuales y colectivos a nivel nacional e internacional. En la actualidad existen más millonarios en dólares estadounidenses en la RPC que habitantes en Australia. Incluso, el Estado-partido ha comenzado a adoptar la retórica del modelo chino, como atestigua un artículo en el que se critica la concesión del Premio Nobel de la Paz en 2010 a un destacado disidente:

China debe mostrar más determinación y confianza a la hora de elegir su propia ruta de desarrollo, que es distinta del enfoque occidental [...] La comisión de los Premios Nobel no tomó una buena decisión, pero ni esto ni la fuerza política que ello representa pueden determinar el futuro crecimiento de China [...] Los éxitos de China tienen más voz que el Premio Nobel de la Paz. ${ }^{19}$

Las palabras "modelo chino" (Zhongguo mushi) y "Consenso de Pekín" (Beijing gongshi) son ahora moneda corriente y objeto de atento examen académico fuera de China. ${ }^{20}$

Por ello, no sorprende que periodistas, intelectuales y académicos hayan intentado identificar un modelo chino. Todos han tratado de definir las principales características del desarrollo de la RPC, y sus resultados son tan dispares en lo que respecta a las dimensiones del modelo chino, que casi es

18. Datos estadísticos sobre la renta de 2007 en "China's GDP grows annual average of $9.67 \%$ from 1978 to 2006", en Xinhua [Agencia de noticias Nueva China], 6 de mayo de 2007. 1 USD $=6.7$ yuanes. Un coeficiente de Gini del 0.4 suele considerarse una premonición de tensión social.

19. "2010 Nobel Peace Prize a disgrace", Global Times, 9 de octubre de 2010.

20. Véase, por ejemplo, Yu Keping, "Zhongguo mushi: Jiedu" ["Comprender el modelo chino"], Zhongguo yuanyang quanwu gongbao [China marítima], núm. 1, 2006, p. 18; "Beijing gongshi yu Zhongguo Mushi" ["El Consenso de Pekín y el modelo chino"], Renmin luntan [Foro del pueblo], núm. 12, 2008, pp. 20-23. 
divertido. Veamos algunos ejemplos: el modelo chino es intrínsecamente neoliberal, afirma David Harvey. ${ }^{21}$ El modelo chino es la antítesis del capitalismo neoliberal, declara Giovanni Arrighi. ${ }^{22}$ El modelo chino combina la reforma económica y la ausencia de cambio político, explica Martin Jacques. ${ }^{23}$ El modelo chino no habría sido sostenible, argumenta Suisheng Zhao, sin la reforma política que ha acompañado a la reestructuración económica. ${ }^{24} \mathrm{El}$ modelo chino se basa sobre todo en la privatización, sostiene Steven Halper. ${ }^{25}$ El modelo chino se suele confundir con la privatización, dice Barry Naughton, que destaca los papeles que las entidades tanto públicas como privadas han tenido en el éxito del desarrollo económico. ${ }^{26}$

Por una parte, nadie debería sorprenderse demasiado por esta falta de acuerdo. La mayoría de los conceptos que resultan útiles, especialmente si son objeto de análisis, provocan acalorados debates. No hay más que pensar en el "poder blando", la "clase" o incluso "el Estado". El estudio de estas ideas distintas puede ayudar a comprender el fenómeno que todas tratan de describir y la dinámica de la situación que se está analizando.

Antes de estudiar las distintas interpretaciones y explicaciones del modelo chino, conviene tener en cuenta tres cosas. La primera es la dimensión ideológica de la discusión. Puede que la Guerra Fría terminara hace más de 20 años, pero los puntos de vista expresados por muchos de los autores que participan en el debate sobre el modelo chino se asientan sobre disputas de aquellos lejanos años. La alabanza del capitalismo estadounidense y su superioridad que hace Halper obedece en gran medida a estas consignas. Arrighi, Harvey y Jacques no ocultan el desagrado que les produce ese mismo capitalismo estadounidense. El segundo punto que se debe tener en cuenta es el peligro del esencialismo aplicado a China, y especialmente de interpretar el presente según parámetros que pertenecen a periodos anteriores al desarrollo

21. David Harvey, A Brief History of Neoliberalism. Nueva York: Oxford University Press, 2007, capítulo 4.

22. Giovanni Arrighi, Adam Smith in Beijing: Lineages of the Twenty-First Century. Londres: Verso, 2007.

23. Martin Jacques, When China Rules the World: The Rise of the Middle Kingdom and the End of the Western World. Londres: Allen Lane, 2009, p. 12.

24. Suisheng Zhao, "The China Model: Can it replace the Western model of modernization?", Journal of Contemporary China, vol. 19, núm. 65, junio, 2010, p. 424.

25. Stefan Halper, The Beijing Consensus: How China's Authoritarian Model will dominate the Twenty-First Century. Nueva York: Basic Books, 2010, pp. 11 y 209.

26. Barry Naughton, "China's Distinctive System: Can it be a model for others?", Journal of Contemporary China, vol. 19, núm. 65, junio, 2010, p. 451. 
de China. Por ejemplo, Jacques tiene toda la razón del mundo al considerar a China un continente y no un simple Estado-nación, pero se equivoca al atribuir a los antiguos imperios características de un Estado-nación, como las fronteras. ${ }^{27}$ Del mismo modo, la descripción que hace Arrighi de la dinastía Song del sur (1127-1279) como un "Estado-nación" con un "mercado nacional" parece ir demasiado lejos como ejercicio de historia comparada. ${ }^{28}$ La suposición de Ramo de que el mandarín, un idioma creado en el siglo xx, se hablaba en todo el imperio ${ }^{29}$ bajo dinastías anteriores es tan interesante como la observación realizada mucho antes por Braudel, que afirmaba que los chinos eran vegetarianos. ${ }^{30}$ En tercer lugar, el análisis del que hablamos está sometido a un proceso de evolución en el que las publicaciones más recientes aprovechan y discuten las aportaciones de autores que han publicado anteriormente. Por ello, las distintas opiniones sobre el modelo chino se examinarán en el orden en que fueron impresas.

\section{Joshua Cooper Ramo}

La primera descripción actual de un modelo chino aparece en el folleto de Joshua Cooper Ramo sobre el Consenso de Pekin. ${ }^{31}$ La argumentación de Ramo se ocupa sobre todo del impacto político internacional del crecimiento de China desde 1978, y no de los detalles de la dinámica del desarrollo en sí, aunque, por supuesto, en el proceso de su argumentación ofrece explicaciones relativas a dicha dinámica. La aparición del Consenso de Pekín se produce en el contexto de las crisis económicas globales de finales de los años noventa y del "fracaso del Consenso de Washington". En palabras de Ramo:

[...] las ideas esenciales de lo que está sucediendo en China (innovación, asimetría, preocupación por la igualdad, la exploración de nuevas ideas de ciudadanía) atraen a naciones que tienen ambiciones de desarrollo y seguridad,

27. Martin Jacques, When China Rules the World: The Rise of the Middle Kingdom and the End of the Western World. Londres, Allen Lane, 2009, p. 12.

28. Giovanni Arrighi, Adam Smith in Beijing: Lineages of the Twenty-First Century. Londres: Verso, 2007, p. 321.

29. Joshua Cooper Ramo, The Beijing Consensus. Londres: The Foreign Policy Centre, mayo 2004, p. 31.

30. Fernand Braudel, A History of Civilizations. Londres: Penguin, 1995, p. 187.

31. Joshua Cooper Ramo, The Beijing Consensus. Londres: The Foreign Policy Centre, mayo 2004. 
pero llevan cientos de años viendo fracasar modelos de desarrollo demasiado dependientes de la ayuda de las naciones desarrolladas (p. 60).

Según esta interpretación, el Consenso de Pekín posee tres características principales: desarrollo basado en la innovación, éxito económico medido no por el crecimiento del PIB per cápita sino por su sostenibilidad y nivel de igualdad, y un fuerte principio de autodeterminación para China y para otros países en sus relaciones con Estados Unidos. No hay duda de que la tercera característica es la de más peso en esta interpretación. Ramo explica claramente por qué atrae la RPC a muchos de los países menos desarrollados del mundo. Existe una oposición al Consenso de Washington y, en concreto, resistencia frente al propio Washington. Es posible que cada país afronte los distintos procesos de la globalización según sus propias condiciones, sin someterse a la dirección de la costa Este de Estados Unidos. En la misma línea, también se insiste en que los países no deben interferir en los asuntos internos de los demás países, actitud que la RPC califica de ataque contra la soberanía. La RPC influye dando ejemplo, no recurriendo a las armas, y los demás países aceptan su mayor influencia económica a través del comercio, la inversión y la ayuda. Esta mayor influencia internacional ha ayudado a la RPC a desarrollar la capacidad asimétrica necesaria para contrarrestar a Estados Unidos mediante lo que suele describirse como "poder blando". Como puede suponerse, este tercer punto y su visión del mundo han sido ampliamente adoptados en la propia RPC. ${ }^{32}$

Los dos primeros puntos de la descripción que hace Ramo del Consenso de Pekín tienen más que ver con la dinámica interna del cambio, y ambos deben estudiarse con más detalle. A primera vista el desarrollo de la RPC ha tenido poca relación con la innovación. De hecho, una de las críticas que suelen hacer los economistas externos es que gran parte de la economía de la RPC ha sido desarrollada por gestores y personas a cargo de los recursos, mediante actividades cuyo único objetivo es obtener beneficios, y no mediante el desarrollo de nuevas ideas y nuevas tecnologías. Ésta no es la opinión de Ramo, desde luego. Este autor argumenta que, dado lo tardío del desarrollo de la RPC, ésta no necesita recorrer las primeras etapas y puede limitarse a importar la tecnología más avanzada ab initio (p. 11). Del mismo modo, la

32. Véase, por ejemplo, Cai Tuo, Quanqiuhua yu zhengzhide zhuanxing [Globalización y transformación política]. Pekín: Peking University Press, 2007. 
afirmación de que la RPC no establece objetivos de crecimiento del PIB es un tanto extraña, pues se trata de un sistema en el que los funcionarios locales tienen programas de incentivos que incluyen objetivos de crecimiento del PIB como indicadores clave de su rendimiento. ${ }^{33}$ En este punto la argumentación de Ramo corre el peligro de perderse en su propia retórica: el crecimiento es fundamental, pero el PCC también prima la productividad total de los factores y puede, como ha demostrado desde 2005, restar importancia al crecimiento económico en sí para alcanzar otras metas de aumento del bienestar (y de mayor gasto dedicado a dicho bienestar). ${ }^{34}$

\section{Giovanni Arrighi}

Los intereses generales de Giovanni Arrighi también subyacen en su explicación del ascenso de China. En su libro Adam Smith en Pekin ${ }^{35}$ existe revisionismo histórico a gran escala, que se centra en Asia Oriental pero cuyo tema es en realidad la política exterior de EUA. Aunque no interpreta la influencia del ascenso de China sobre los países menos desarrollados como Ramo, estudia los defectos, en su opinión, de la política exterior de EUA, al que critica por su intervención en Oriente próximo, no alegando razones morales, sino porque ello ha desviado una parte desproporcionada de la atención del gobierno de Estados Unidos hacia esa región. En el contexto en el que nos encontramos, intentar comprender el modelo chino, la contribución de Arrighi consiste en tratar de desconectar a Adam Smith del neoliberalismo y afirmar que Smith no sólo reconocería sino que alabaría la alternativa china al capitalismo estadounidense:

[...] el fracaso del Proyecto para el Nuevo Siglo Estadounidense y el éxito del desarrollo económico chino, unidos, han hecho que la visión de Smith, un mercado mundial basado en una mayor igualdad entre todas las civilizaciones, sea más posible que nunca desde la publicación, hace casi dos siglos y medio, de $L a$ riqueza de las naciones (p. 8).

33. Sasac, "Provisional Methods for Assessing Performance of Responsible Managers of Central Enterprises", 30 de diciembre de 2006, en: http://www.sasac.gov.cn/gzjg/yjkh/200701310039. htm

34. Jane Duckett y Beatriz Carrillo (eds.), China's Changing Welfare Mix. Abingdon: Routledge, 2011.

35. Giovanni Arrighi, Adam Smith in Beijing: Lineages of the Twenty-First Century. Londres: Verso, 2007. 
Los argumentos de Arrighi cuestionan la interpretación neoliberal de la globalización del capital. Revisando las obras de Adam Smith y de Marx, y estudiando la "enorme divergencia" existente entre los patrones de desarrollo económico de Asia Oriental y Europa durante el siglo XIX, Arrighi identifica una tradición de economía de mercado no capitalista en Asia Oriental. Examina el desarrollo de China adoptando una perspectiva a largo plazo, y afirma que, tanto bajo la dinastía Ming (1368-1644) como bajo la dinastía Qing (1644-1911), la denominación más exacta del sistema económico era la de capitalismo mercantil. Esta economía de mercado es la que explica, según Arrighi, la historia económica de China desde 1850, incluido su espectacular crecimiento en las últimas tres décadas. En la base de esta distinción entre economías capitalistas y economías de mercado se encuentra la cuestión de la relación de la mano de obra con la producción. Mientras que la economía de mercado de Asia Oriental utiliza tradicionalmente de forma intensiva la mano de obra, la tradición capitalista de Europa y de Estados Unidos expropia la mano de obra del productor directo.

A diferencia de quienes hacen hincapié en el desarrollo de un sector privado en la RPC como característica definitoria de la reforma de la economía, Arrighi sostiene que

[...] la desregulación y la privatización han sido mucho más selectivas, y mucho
más lentas, que en los países que han seguido fórmulas neoliberales. De hecho, la
principal reforma no ha sido la privatización, sino la competencia de las empresas
estatales entre sí, con empresas extranjeras y, sobre todo, con una gran variedad
de empresas comunitarias, semiprivadas y privadas de reciente creación (p. 356).

Mientras que el neoliberalismo exige que el Estado no intervenga directamente en la gestión de la economía, según Arrighi el papel del gobierno en la economía de la RPC está lejos de desaparecer. Al contrario, Arrighi sostiene que la acción del gobierno ha resultado decisiva para establecer y fomentar una industrialización basada en las exportaciones, especialmente, entre otras cosas, a través de la creación de zonas democráticas de exportación en el delta del río Perla y en el delta del río Yangtsé. El gobierno también ha desempeñado un papel fundamental promoviendo la inversión extranjera y, en general, reforzando el desarrollo de una "economía nacional dedicada a sí misma, protegida de manera no oficial por el idioma, las costumbres, las instituciones y las redes accesibles a los extranjeros sólo mediante intermediarios locales". 


\section{Martin Jacques}

Martin Jacques, en When China Rules the World, ${ }^{36}$ enfoca de forma similar el ascenso de China durante las últimas tres décadas y su posible futuro, especialmente su interacción con el resto del mundo, adoptando una perspectiva histórica a largo plazo. Según Jacques, no puede juzgarse a China igual que a otros países:

La actitud occidental dominante ha establecido que los fundamentos del mundo se verán poco afectados por el ascenso de China. Esta actitud se basa en tres suposiciones principales: que la naturaleza del desafío chino será sobre todo económica, que al final China se comportará como una típica nación occidental y que el sistema internacional seguirá básicamente como hasta ahora, con China aceptando el statu quo y convirtiéndose en un miembro perfectamente integrado en la comunidad internacional. Las tres suposiciones son erróneas. El ascenso de China cambiará profundamente el mundo [...] Pero resulta inconcebible que China se convierta en una nación al estilo occidental al que estamos acostumbrados. China es producto de una historia y una cultura que tienen poco o nada en común con las occidentales (pp. 12 y 13).

Jacques identifica varias diferencias fundamentales a partir de su estudio de la historia de China, que distinguen el desarrollo actual de este país y su desarrollo futuro más probable de los del resto del mundo. El punto de partida es que China debe considerarse un "Estado-civilización" y no un Estado-nación, sobre todo por su tamaño y su perspectiva histórica. Esto, por supuesto, no es ninguna novedad en el estudio de China, y refleja los análisis de la sinología de mediados del siglo $\mathrm{xx} .{ }^{37}$ En el pasado, las relaciones de China con otras partes del mundo se rigieron no por un sistema de dominación militar, sino por la simbiosis política de un sistema tributario. Jacques sugiere que éste es también el futuro más probable, de una forma que recuerda a la descripción de Ramo del desarrollo de capacidad asimétrica por parte de la RPC para contrarrestar la influencia de Estados Unidos.

36. Martin Jacques, When China Rules the World: The Rise of the Middle Kingdom and the End of the Western World. Londres: Allen Lane, 2009.

37. Véase, por ejemplo, Joseph Levenson, "The province, the nation and the world: the problem of Chinese identity", en Albert Feuerwerker, Rhoads Murphey y Mary C. Wright (eds.), Approaches to Modern Chinese History. University of California Press, 1967, pp. 268-288. 
Resulta evidente que el tamaño y la escala de China son una diferencia importante, y Jacques lo aprovecha bien (p. 227). En la RPC encontramos una gran variedad de culturas y prácticas sociales. Los ejemplos más obvios de lo anterior son los pueblos no chinos de la RPC, los zhuang, los tibetanos, los uigures, los mongoles y un total de 55 nacionalidades diferentes a la china. No obstante, y como el mismo Jacques señala, las zonas chinas de China también presentan una gran variedad de idiomas, culturas, relaciones sociales e incluso patrones de desarrollo económico. La escala y el tamaño también son importantes en el sentido de que China cuenta con un vasto mercado interno. Al igual que Estados Unidos y posiblemente la India, aunque pueda preferir interactuar económica y socialmente con el resto del mundo, no lo necesita demasiado. Como sucede con Estados Unidos, China podría ser una economía autosuficiente.

La escala y el tamaño también confieren a los chinos una actitud respecto a la raza y la identidad étnica que los distingue del resto del mundo. Esta diferencia en la consideración de "los otros" consiste tanto en una mayor tolerancia de la variedad social como en una mayor insistencia en la aceptación de la conformidad, o al menos de la necesidad de conformidad. Esto, por supuesto, es una de las razones de otra diferencia fundamental: el sistema de gobierno chino sigue siendo autoritario e intocable. Jacques no lo dice explícitamente, pero de su análisis parece desprenderse que esto también puede aplicarse al futuro.

Las últimas tres diferencias fundamentales que indica Jacques se refieren al proceso de desarrollo en sí mismo. Una es la velocidad de transformación, que ha sido sorprendentemente rápida. Durante el "gran salto adelante" (19581960) la RPC adoptó el lema de "Alcanzar y superar la Revolución Industrial británica en 15 años: conseguir que cada uno de nuestros días equivalga a 10 de los suyos". Durante las últimas tres décadas el desarrollo se ha acercado a esa meta más de lo que se podía imaginar en los últimos años de la década de los cincuenta. Al describir la velocidad de esta transformación, Jacques está a punto de permitir que su retórica también se acelere: "La modernidad china [...] se distingue por la velocidad de la transformación del país. Combina, de una forma bastante distinta a la experiencia occidental de modernidad, el pasado y el futuro en uno y al mismo tiempo en el presente" (p. 425). La segunda observación sobre el desarrollo hace referencia a que, aunque China sigue siendo comunista, es evidente que no se trata de una experiencia de comunismo al estilo de la Unión Soviética (p. 427). En tercer lugar, China, 
de forma un tanto paradójica, seguirá siendo un país desarrollado en vías de desarrollo durante algún tiempo, debido en gran parte, de nuevo, al tamaño y a la escala de la RPC.

\title{
Stefan Halper
}

La versión de Stefan Halper del Consenso de Pekín ${ }^{38}$ es radicalmente distinta, entre otras cosas porque considera a China una amenaza, el principal obstáculo para la hegemonía de Estados Unidos, que debe ser vencido.

\begin{abstract}
Pekín es, cada vez más, una clara amenaza para Washington, pero los términos del desafío todavía no han tomado forma en la conciencia colectiva ni, desde luego, en los círculos políticos. China evita la confrontación directa, y su verdadero desafío se presenta en un campo completamente distinto, que es el poder de transformación y el protagonismo de Pekín en el ascenso de una especie china de capitalismo y de una concepción china de la comunidad internacional, ambas opuestas a su versión occidental, y muy diferentes de ella. En la batalla global entre distintas visiones del futuro y diferentes versiones del capitalismo, China es la protagonista. En un momento en el que los centros tradicionales de poder en Occidente (como el Fondo Monetario Internacional y el Banco Mundial) se ven burlados y desautorizados por el abundante capital chino, estos nuevos paladines no occidentales del mercado libre están derrotando a Occidente en su propio terreno (p. 11).
\end{abstract}

A diferencia de los autores de los que hemos hablado hasta ahora, Halper ve en el ascenso de China el triunfo de la reforma del mercado liberal.

Halper argumenta que, con el debido respeto a Ramo, el atractivo de China reside precisamente en su capitalismo desenfrenado, que permite a los países en vías de desarrollo crecer económicamente sin someterse a "las condiciones financieras de Occidente”. Puede que ésta sea la principal crítica de Halper a China. La reforma del mercado liberal ha permitido a la RPC ofrecer "suficientes oportunidades económicas, y un mejor nivel de vida, para persuadir al pueblo de que en el futuro le espera una mayor calidad de vida".

En un país del tamaño de China, esta política sólo ha sido posible gracias a las empresas privadas y la economía de escala, que pueden garantizar un número

38. Stefan Halper, The Beijing Consensus: How China's Authoritarian Model will dominate the Twenty-First Century. Nueva York: Basic Books, 2010. 
suficiente de empleos para los millones de personas que abandonarán las empresas estatales y las redes de protección social comunistas. Por lo tanto, la estabilidad interna depende de la capacidad de alimentar el rápido crecimiento económico, año tras año. A su vez, esto exige tener acceso a mercados y recursos extranjeros, los suficientes para que la cadena se mantenga en movimiento y sus productos desaparezcan de las tiendas. Esto significa tener acceso a África para conseguir petróleo, mineral de hierro, cobre, cinc, plomo, estaño y uranio. Y a Latinoamérica, para conseguir soja, acero y más petróleo. Significa que es necesario conseguir contratos para mantener la facturación de los gigantes de la construcción y las telecomunicaciones, que crecen rápidamente. Significa tener acceso a mercados, desde Europa hasta Asia meridional, donde se consuma el interminable flujo de textiles, zapatos, prendas, aparatos eléctricos, productos para el hogar y material de oficina procedentes de China.

Pero, según Halper, esta visión neoimperialista también significa que la RPC ha tenido que buscar

[...] hasta al último socio comercial que el mundo le pudiera ofrecer, sin importar su posición en el espectro que va de las dictaduras a las democracias [...] China hace negocios con el bueno, con el feo y con el malo, siempre que paguen [...] Pekín ha trabajado duro en la última década para convertirse en una fuente alternativa de ayuda, comercio, préstamos e inversión para cualquier Estado que no llegue a los niveles occidentales de buen gobierno.

No sólo ofenden a los observadores occidentales los hechos y las dictaduras que esta política contribuye a mantener, sino que además, al parecer, somos incapaces de hacer nada al respecto (p. 209).

Según Halper, la solución es que Estados Unidos organice una campaña internacional más eficaz. En sus propias palabras: "El mayor temor de China son las ideas estadounidenses" (p. 208).

\section{Suisheng Zhao}

Suisheng Zhao adopta una postura más académica y considerablemente más objetiva sobre la cuestión del modelo chino. ${ }^{39}$ Rechaza de plano la manida suposición de que el modelo chino consiste en una reforma económica liberal

39. Suisheng Zhao, "The China Model: Can it replace the Western model of modernization?", Journal of Contemporary China, vol. 19, núm. 65, junio, 2010, pp. 419-436. 
sin cambio político. En su lugar, cuestiona cuál es la dimensión exacta del funcionamiento del mercado libre y la dimensión exacta del autoritarismo. En ambos casos sostiene que las cosas no son blancas ni negras: lo que predomina son los tonos de gris.

En lo que se refiere a economía de mercado libre, Zhao señala que China carece de muchas de las instituciones y estructuras que suelen estar asociadas a un mercado libre. Aún no existen tribunales independientes. A pesar de que el sistema legal y político actual reconoce los derechos de propiedad, no siempre se respetan éstos. El gobierno no es perceptible ni sistemáticamente transparente, y no existe el derecho ni el ejercicio de la libre información. El Estado continúa desempeñando un importante papel económico, pues controla parcelas estratégicas de la economía y sectores estratégicos: servicios públicos básicos, transporte, comunicaciones, medios de comunicación, finanzas (p. 422).

Para Zhao, el modelo chino es una versión del siglo xxI del Estado desarrollista de Asia Oriental ${ }^{40}$ con tres características principales: acción y pragmatismo económicos, comportamiento de Estado desarrollista y control estatal de las ideas:

Lo que hace único al modelo chino es que el régimen comunista ha conservado su propio espacio político para decidir cuándo, dónde y cómo adoptar las ideas occidentales. En concreto, aunque el Estado chino haya adoptado la mayor parte de los principios básicos del Consenso de Washington, especialmente su énfasis en el papel del mercado, del emprendimiento, de la globalización y del comercio internacional, rechaza o modifica los aspectos liberales que reducen enormemente el papel del Estado. Por ejemplo, aunque el Estado ha abierto gradualmente la economía interna a la competencia internacional, continúa protegiendo la industria naciente y los sectores más importantes (p. 424).

Al mismo tiempo, Zhao insiste bastante en que también ha habido reforma política, pero una reforma política en consonancia con el enfoque de Estado desarrollista. No se ha introducido una democracia liberal, pero de una manera verticalista se ha institucionalizado el sistema de liderazgo, el esfuerzo por conseguir que el gobierno sea más receptivo a una sociedad cada vez más plural,

40. Robert Wade, Governing the Market: Economic Theory and the Role of Government in East Asian Industrialization. Princeton University Press, 1990; Meredith Woo-Cummings, The Developmental State. Cornell University Press, 1999. 
un aumento de los derechos constitucionales de los ciudadanos y la transición del PCC de partido revolucionario a partido en el poder. Estos indicadores de cambio son muy importantes para un sistema político que durante los años en los que la política china estuvo dominada por Mao, fue tremendamente personalista y arbitrario, no sólo en lo referente a los cuadros dirigentes sino también de cara a los ciudadanos. Se suele atribuir a Deng Xiaoping el mérito de ser el precursor del espectacular crecimiento económico, pero su principal contribución a la era reformista fue la restauración de la democracia interna del PCC y el esfuerzo por recuperar la legitimidad de la RPC. ${ }^{41}$

Según la interpretación que hace Zhao del modelo chino, este enfoque del desarrollo consigue que la RPC sea muy atractiva para otros países, especialmente para aquéllos en vías de desarrollo. Se presenta como un enfoque desideologizado, que favorece tanto el crecimiento económico como la estabilidad social y preserva el poder de un régimen autoritario. La RPC también resulta atractiva porque destaca una postura no intervencionista y sin prejuicios en sus relaciones con otros países, y todo esto en un momento en el que "Occidente" es mucho menos atractivo debido a su intervención en Irak (p. 431).

\section{Barry Naughton}

La última interpretación del modelo chino que analizaremos aquí niega en realidad la propia existencia de tal modelo. Barry Naughton, ${ }^{42}$ en su intento por describir la experiencia de desarrollo de la RPC durante los últimos 30 años, sostiene que, dada la imposibilidad de reproducir en ningún otro lugar lo que ha sucedido, no tiene sentido hablar de modelos (p. 439). Identifica tres características exclusivas de esa experiencia, que la hacen única. Estas características son el tamaño de China y las posibilidades que ofrece un gran mercado interno, la aparición de una nueva industria basada en un desarrollo que utiliza de forma intensiva la mano de obra tras un periodo de socialismo de Estado basado en un desarrollo que utilizaba de forma intensiva el capital,

41. David S. G. Goodman, Deng Xiaoping and the Chinese Revolution: A political biography. Londres: Routledge, 1994; David S. G. Goodman, "The Chinese Political Order after Mao: 'Socialist Democracy' and the exercise of state power", Political Studies, vol. 33, núm. 2, junio 1985, pp. 218-235.

42. Barry Naughton, "China's Distinctive System: Can it be a model for others?", Journal of Contemporary China, vol. 19, núm. 65, junio, 2010, pp. 437-460. 
y el mantenimiento y la reestructuración del sistema autoritario jerárquico de China.

Naughton comienza criticando las interpretaciones de la experiencia de desarrollo de China que destacan su pragmatismo y flexibilidad (y, en concreto, la obra de Joshua Cooper Ramo), y sostiene que estas características no son suficientes para explicar el éxito de la RPC. Como señala, muchos otros países han sido pragmáticos y flexibles a la hora de afrontar el desarrollo, y no han conseguido tasas de crecimiento tan espectaculares. En lo que Naughton hace hincapié es en la economía mixta de la RPC, constituida por un sistema empresarial de tres capas: grandes empresas dirigidas por el gobierno central, empresas híbridas locales y extranjeras, y capitalismo a pequeña escala. ${ }^{43}$ Según Naughton, la responsable del éxito es la dinámica entre los sectores público y privado gestionada por el Estado-partido.

No obstante, Naughton destaca seis aspectos del desarrollo económico de la RPC que considera fundamentales para el éxito obtenido hasta la fecha, aspectos de los que otros pueden aprender. El primero de ellos es que no se ha abandonado la propiedad pública, que ha demostrado ser "bastante eficaz". De hecho, ahora la RPC cuenta con un sistema industrial mixto. Continúa siendo un sistema de desarrollo basado en el mercado, en el que las empresas privadas predominan en los sectores en los que se fomenta la competencia, pero la propiedad estatal predomina en sectores considerados estratégicos para el desarrollo económico o la estabilidad social: transporte, energía, fármacos, finanzas, comunicaciones, minería. Se trata de un sistema mixto y equilibrado en el que la dirección del Estado-partido controla y puede modificar dicho equilibrio (p. 442). El segundo aspecto consiste en que se fomenta la competencia en todos los sectores, excepto en los considerados estratégicos, y sigue siendo más importante que la propiedad.

Naughton pone el ejemplo del reestructurado sector chino de las telecomunicaciones, en el que tres empresas, aunque estatales, han sustituido al antiguo monopolio público. Compara la calidad del servicio ofrecido con lo que sucede en México, donde una regulación deficiente y la falta de competencia han creado precios altos, mal servicio y el hombre más rico del

43. Arthur Kroeber, "Rising China and the liberal West", China Economic Quarterly, marzo 2008; Dieter Ernst y Barry Naughton, "China's emerging industrial economy: Insights from the IT industry", en Christopher A. McNally (ed.), China's Emergent Political Economy: Capitalism in the Dragon's Lair. Nueva York: Routledge, 2008, pp. 39-50. 
mundo (p. 445). El compromiso con la competencia en un gran mercado nacional supone toda una diferencia, según Naughton:

A diferencia de lo que sucede en economías de menor tamaño, el sistema político de China está obligado a reconocer la existencia de distintos grupos de interés y aspirantes al poder. Los líderes chinos actúan como si su control del poder fuera siempre algo difuso, y dependiera de los buenos resultados económicos. Siempre hay varios candidatos esperando entre bastidores, preparados para salir a escena si así lo ordena el poder. La diferencia es importante si lo comparamos con un sistema político capaz de unirse para apoyar los intereses de una camarilla formada por muy pocas personas, como sucedía con Marcos en Filipinas. Las políticas muy ineficaces y la corrupción extrema suelen representar un grave problema para los líderes. China no se ve menos afectada por las malas políticas o la corrupción que otros países, pero puede decirse que la gravedad de ambas se mantiene a raya gracias a la competencia política (p. 445).

La tercera característica destacada por Naughton es que la propiedad pública se utiliza para explotar el poder del mercado y para generar beneficios mediante la creación de bienes públicos e inversiones. Naughton destaca los aspectos propios de un Estado desarrollista presentes en la economía de la RPC, refrendando la interpretación de Zhao. Señala el aumento de los beneficios de las empresas estatales, especialmente durante los últimos cinco años $\mathrm{y}$, lejos de sentirse alarmado por ello, sostiene que refuerza la capacidad del Estado-partido para dirigir la estructuración de la economía, sobre todo en lo referente a la gestión de la competencia y a su capacidad de garantizar la permanencia de dicha competencia.

En cuarto lugar, Naughton destaca la importancia de una estrategia de crecimiento basada en la inversión. A diferencia de lo que sucede en una economía neoliberal idealizada o muy privatizada, se considera deseable invertir antes de que exista demanda y crear una capacidad que pueda utilizarse más adelante. Esto también se debe al hecho de que sea el Estado el encargado de dirigir la estructuración de la economía. Al mismo tiempo, resulta importante para ampliar la base de apoyo entre la clase media y garantizar el futuro del régimen. La inversión previa a la existencia de demanda, por ejemplo, ha creado la infraestructura de carreteras, ferrocarriles y rutas aéreas necesaria para permitir mayor movimiento de personas y mercancías. La única condición de estas inversiones previas debe ser que estén destinadas a aumentar la productividad (p. 451). 
La quinta característica del desarrollo económico que señala Naughton consiste en que el sector estatal ha sido y sigue siendo capaz de crear oportunidades para crecer y obtener beneficios fuera del sector estatal. Una vez más, no se trata de una simple mezcla de lo público y lo privado, sino de un intento deliberado por mantener el equilibro durante el desarrollo. Lo privado hace su aportación a lo público con los impuestos, pero también puede beneficiarse de las inversiones.

El último aspecto del desarrollo económico de la RPC que Naughton considera un posible ejemplo para otros, es que los responsables de las empresas estatales están sometidos a las fuerzas del mercado, a pesar de desempeñar sus funciones en empresas sin competencia (en la mayor parte de los casos). Su motivación para conseguir mejores resultados económicos proviene de la vinculación de su remuneración con la capacidad de su empresa para maximizar el valor de sus activos, la eficiencia y los resultados, en un sistema establecido por el organismo estatal responsable de la supervisión de las empresas estatales. Estos comentarios llevan inevitablemente a Naughton a observar que

No se puede afirmar que en China no haya habido reforma política; lo que sucede es que las reformas políticas realizadas han creado una nueva y eficaz jerarquía autoritaria. El resultado es un sistema en que tanto la vigilancia y la supervisión estatales, como los incentivos del mercado son inusitadamente fuertes. El sistema no tiene fisuras. Los funcionarios y responsables tienen una gran autoridad y fuertes tentaciones, pero también están sometidos a una férrea vigilancia y a castigos draconianos (p. 457).

Esta observación también respalda los comentarios de Zhao sobre el Estado desarrollista y la reforma política.

\section{Explicación del éxito}

Existen diferencias inevitables entre estos intentos de explicar el éxito del desarrollo chino durante las tres últimas décadas, sobre todo por sus distintos puntos de partida e intereses. Ocasionalmente también se producen conflictos, aunque sorprende su escasez, dada la complejidad del tema y la rapidez del cambio. Desde luego, el estudio de estas diversas explicaciones permite descubrir las estructuras y los elementos dinámicos que se encuentran tras la experiencia de desarrollo de China durante las tres últimas décadas. También deja claro que, a pesar de la retórica utilizada para referirse al "modelo chino", 
existen pocas posibilidades de reproducirlo, como señala Barry Naughton, por lo que en ese sentido no puede hablarse de la existencia de un modelo. El éxito del desarrollo de la RPC se basa en dos circunstancias únicas, que constituyen los cimientos de dicho éxito: su tamaño y escala, y la historia de su trayectoria de desarrollo. Al mismo tiempo, existen otros factores en el pasado reciente de la RPC de los que podrían aprender los demás países.

Una de las características exclusivas más importantes para el éxito de China es el tamaño y la escala del país y, por tanto, su economía. Se ha hablado mucho del crecimiento de China y de su condición de segunda mayor economía del mundo (por PPA). El crecimiento y los logros son espectaculares. Al mismo tiempo, contar con la mayor población del mundo significa que China ha sido siempre una gran economía, y que el impacto de cambios relativamente menores en las rentas individuales puede magnificarse cuando consideramos la economía en su conjunto. Fue la mayor economía del mundo hasta 1830, y sólo dejó de serlo cuando la industrialización hizo crecer desproporcionadamente el PIB per cápita en Europa y Estados Unidos. Aun así, entre 1830 y 1978, periodo durante el que el crecimiento económico de China fue débil, el país nunca bajó del cuarto puesto entre las mayores economías del mundo. ${ }^{44}$ Una consecuencia de ello es que el gasto público puede aumentar considerablemente, dados los recursos con los que cuenta el Estado.

El tamaño de China también permite explicar la supuesta excepción a la regla que suponen 30 años con una tasa de crecimiento anual de $9-10 \%$ y una inflación relativamente baja. Por supuesto han existido presiones inflacionarias $\mathrm{y}$, como en otras economías, se han resuelto variando los tipos de interés. No obstante, en el caso de China el concepto de tasa de crecimiento nacional oculta la ausencia de integración de la economía o, para ser más exactos, la lentitud de la integración económica de las regiones de China. Existen 13 regiones económicas poco integradas, y las comunicaciones siguen siendo difíciles entre el norte y el sur, y hasta cierto punto incluso entre el este y el oeste, a pesar de contar con dos importantes sistemas fluviales (el río

44. Angus Maddison, Chinese Economic Performance in the Long Run 960-2030 AD. París: OECD Publishing-Development Centre Studies, 2007. Angus Maddison (Autor)

Todos los libros, información sobre el autor, etc.

Vea los correspondientes a este autor ¿Escribe? 
Amarillo en el norte, el río Yangtsé en el sur). ${ }^{45}$ Esta ausencia de integración explica, por ejemplo, la necesidad que tiene China de importar carbón a pesar de contar con Ordos en el norte, el mejor y mayor yacimiento de carbón del mundo, que bastaría para cubrir todas las necesidades nacionales. ${ }^{46}$ Una tasa media de crecimiento anual de $10 \%$ en toda la nación oculta un proceso en el que primero una región económica (cuyo centro es Cantón) creció a un ritmo muy superior a la media nacional durante unos cuantos años y, después, las demás se desarrollaron a una velocidad similar.

La escala continental y el tamaño de China significan también que cuenta con un vasto mercado interno poco desarrollado hasta la fecha. El desarrollo se ha concentrado sobre todo en la costa oriental, donde se encontraban las primeras industrias de la era reformista, basadas en las exportaciones. La apertura del interior es un obvio y antiguo reto ${ }^{47}$ para que China pueda imitar a los países desarrollados del mundo y generar una proporción del PIB mundial mayor que la de su población. ${ }^{48}$ Las estructuras necesarias para ello se crearon en una fase relativamente temprana del desarrollo de las reformas en la RPC, con la introducción del federalismo fiscal. ${ }^{49}$

El segundo conjunto de circunstancias únicas en el éxito económico de la RPC se debe a la trayectoria de su desarrollo antes y después de 1978. Existe un aspecto del desarrollo en la experiencia económica de reforma en la RPC que suele pasarse por alto. Inmediatamente después de 1978 comenzó una tímida reforma, y el crecimiento económico necesitó una serie de impulsos antes de empezar a moverse en la dirección actual. No conviene olvidar tampoco que la era reformista no surgió de la nada. Como indica Naughton, y como también

45. C. W. Kenneth Keng, "China's Future Economic Regionalization", Journal of Contemporary China, vol. 10, núm. 29, noviembre 2001, pp. 587-611.

46. David S. G. Goodman, "King Coal and Secretary Hu: Shanxi’s Third Modernisation", en Hans Hendrischke y Feng Chongyi, The Political Economy of China's Provinces: comparative and competitive advantage. Londres: Routledge, 1999, pp. 211-244.

47. David S. G. Goodman (ed.), China's Campaign to 'Open Up the West': National, provincial and local perspectives. Cambridge University Press, 2004.

48. En 2003 la RPC produjo aproximadamente 15.1\% del PIB mundial, con $20.5 \%$ de la población del mundo. Esto contrasta con la situación de Estados Unidos, que produjo $20.6 \%$ del PIB mundial, con $4.6 \%$ de la población del mundo, y con la de Europa, que produjo $21.1 \%$ del PIB mundial con $8.2 \%$ de la población del mundo. Fuente: Angus Maddison, Chinese Economic Performance in the Long Run 960-2030 AD. París: OECD Publishing-Development Centre Studies, 2007.

49. G. Montinola, Y. Qian y B. R. Weingast, "Federalism, Chinese Style - The Political Basis for Economic Success in China", World Politics, vol. 48, octubre 1995, p. 50. 
han sostenido otros autores, ${ }^{50} 30$ años de socialismo de Estado antes de 1978 proporcionaron las estructuras de un Estado en vías de modernización y una considerable capacidad económica. El desarrollo había utilizado de forma intensiva el capital y su productividad había sido ineficiente. La experiencia de la RPC anterior a 1978 también tuvo como resultado un sistema político centralizado y unificado. Un legado fundamental para la era reformista fue su sistema autoritario y jerárquico.

También conviene tener bien presente la historia de la evolución de la reforma después de 1978. A pesar de que a los analistas de fuera de China les gusta hablar de la flexibilidad y el pragmatismo que parecen caracterizar la experiencia de desarrollo de la RPC, a veces olvidan la dinámica de la experimentación política existente. Existe una importante autonomía local, pero también está sometida al control y a la aprobación del Estado-partido. Compárense los experimentos realizados en Shenzhen para establecer una zona económica especial en los primeros años de la década de los ochenta, ${ }^{51}$ con los realizados para establecer el ideal de "pequeño gobierno, gran sociedad" en Hainan en 1988, cuando esta región adquirió la condición de provincia. ${ }^{52}$ Shenzhen ha tenido un éxito arrollador desde el punto de vista del Estadopartido, y la política de zonas económicas especiales se extiende y desarrolla en gran parte de China. Por el contrario, con los experimentos de Hainan no se consiguió nada, y Pekín les dio carpetazo. El PCC y el Estado-partido en general han demostrado ser organizaciones con una tremenda capacidad de aprendizaje. ${ }^{53}$ Ésta no tiene por qué ser una característica exclusiva del desarrollo de la RPC, aunque existen razones para sospechar que, si la combinamos con la continuidad y el refuerzo de su autoritarismo jerárquico (que es necesario para mantener la disciplina de la organización), pocos países podrán emular este aspecto de la reforma.

Resulta evidente que el papel del PCC ha sido fundamental para el desarrollo de la RPC durante las tres últimas décadas, y no sólo por haber restaurado

50. Peter Nolan, Transforming China: Globalization, Transition and Development. Anthem Press, 2004.

51. Ezra F. Vogel, One Step Ahead in China: Guangdong under Reform. Harvard University Press, 1989.

52. Feng Chongyi y David S. G. Goodman, China's Hainan Province: Economic development and investment environment. University of Western Australia Press, 1995.

53. Linda Chelan Li, "Embedded institutionalization: Sustaining the Rural Tax Reform in China", Pacific Review, vol. 19, núm. 1, 2006. 
su propio orden político y haber creado una nueva estabilidad. Como deja bien claro Bruce Dickson, en el proceso el PCC ha forjado además una alianza estratégica con los nuevos empresarios, cuya aparición ha fomentado:

[...] el partido se ha integrado en el sector privado [...] ha animado a sus miembros, incluidos los funcionarios del gobierno y del partido, a "lanzarse a la piscina" del sector privado, y cada vez más empresarios de éxito se unen al partido. Estos capitalistas rojos representan la integración de la riqueza y el poder, que es la base del comunismo nepotista de China. Esta integración es un elemento fundamental del denominado "Consenso de Pekín": la capacidad de conseguir crecimiento económico sin acompañarlo con reformas políticas. Los capitalistas rojos poseen las mayores empresas, y tienen más posibilidades de participar en las instituciones políticas oficiales de China. Por ello, están más dispuestos a respaldar el statu quo en el que han prosperado, que a buscar una reforma política fundamental. De hecho, los capitalistas rojos son parte del statu $q u o$, no aspirantes a acabar con él. La mayoría de los capitalistas rojos ya estaban en el PCC antes de unirse al sector privado, por lo que su interés por el actual sistema político es aún mayor. En resumen, hay más probabilidades de que la integración de élites económicas y políticas en China contribuya a mantener el actual sistema político autoritario, que de que represente una amenaza directa para el mismo. La estrategia del PCC de integrarse con el sector privado, tanto animando a los actuales miembros del partido a dedicarse a los negocios, como invitando a los empresarios a integrarse en él, continúa reportando beneficios. Se trata de un elemento fundamental de la estrategia de supervivencia del PCC, y hasta ahora funciona. ${ }^{54}$

El ritmo de la reforma, aunque sostenido, no ha sido uniforme. Esto no resulta demasiado sorprendente. La política de la revolución cultural dejó muchas cicatrices, por lo que las personas (tanto en puestos directivos como en la base de la jerarquía social) a veces se resisten a mostrar iniciativa o a actuar de una forma diferente, como ahora les dicen que hagan. El mismo PCC ha dudado a veces sobre cómo proceder, como en 1978-1979, una vez tomada la decisión de acometer la reforma, en 1989, cuando la protesta popular parecía fuera de control, y en 1992, al enfrentarse repentinamente a sus supuestas inseguridades. La reforma económica comenzó en el campo, y sólo llegó a la China urbana en 1984. Queda claro que las interacciones internacionales

54. Bruce J. Dickson, Wealth into Power: The Communist Party's Embrace of China's Private Sector. Cambridge University Press, 2008, p. 238. 
también influyen en esta falta de uniformidad, pues China está ahora más integrada económicamente con el resto del mundo.

Una de estas interacciones fue el importante papel que tuvo la diáspora china en los primeros años de la reforma. En los años ochenta se habló mucho de la mayor integración de China con la región y con la economía global. El vehículo de esta integración fue con frecuencia la emigración china, que, aunque residía en otros países, estaba dispuesta a trabajar con su antiguo "hogar" en beneficio mutuo. Al hablar el mismo idioma, comprender las prácticas y costumbres locales y, sobre todo, poder ofrecer acceso a líderes económicos y personas de relevancia local, la emigración desempeñó un papel fundamental, especialmente en ese momento del desarrollo económico de China. ${ }^{55}$

En un sentido similar, existe un aspecto evolutivo en el patrón de crecimiento económico. Este comenzó, como ya se ha indicado, en el sur, en las provincias de Cantón y Fujian, y en concreto en sus zonas económicas especiales, centradas en el desarrollo de la producción dedicada a la exportación. En estas zonas las cadenas de producción de la industria ligera, los textiles y las prendas se han sustituido progresivamente por actividades más tecnológicas, y las industrias originales se han trasladado al norte y al interior del país. Al mismo tiempo, alrededor del año 2000, aunque la producción dedicada a la exportación continuaba representando una parte importante de la economía (aproximadamente 32\% ) y seguía creciendo, había dejado de ser el sector con mayor aumento anual de su porcentaje en el PIB. Ese lugar lo ocupó entonces la promoción inmobiliaria y, más recientemente, el crecimiento del consumo. ${ }^{56}$

Junto a estas características exclusivas de la experiencia de desarrollo de China, existen otros aspectos que podrían tener mayor interés. Un punto de partida obvio es la introducción de la mercantilización y la competencia, aunque no de la privatización, si bien se suele utilizar este último término para referirse a los anteriores. La diferencia entre mercantilización y privatización es importante por dos motivos cuando se explica el éxito del desarrollo económico de China.

55. Paul J. Bolt, China and Southeast Asia's Ethnic Chinese: State and Diaspora in Contemporary Asia. Praeger, 2000.

56. Cary Huang, "Domestic consumption now top mainland growth driver", South China Morning Post, 16 de enero de 2010; Capital Economics. China Economics Update, 27 de mayo de 2010; Jonathan Anderson, "Is China Export-led?", UBS Investment Research Asian Focus, 27 de septiembre de 2007. 
El primero de esos motivos es que la privatización implica relaciones de propiedad que no podían aplicarse a la RPC hasta el reconocimiento legal de los derechos de propiedad en 2006 y la introducción de la legislación sobre insolvencia en 2008, incluso estas relaciones continuaron siendo más complejas de lo que podría parecer a primera vista. A pesar de que los activos de los sectores colectivo y estatal pueden no estar ya asignados a la empresa inicialmente responsable de su desarrollo, su propiedad raras veces ha pasado a manos de personas físicas, a diferencia de lo que sucede con el control de su uso y disfrute. Es más, aunque existen empresas privadas desde 1984, la mayor parte de estas empresas están estructuralmente condenadas a moverse a pequeña escala, sin posibilidad de acceder a la tierra, la mano de obra y los recursos que necesitan para crecer. Una destacada característica del crecimiento de la economía de la RPC ha sido el desarrollo del sector público colectivo local, que ha pasado a albergar empresas subordinadas a empresas estatales reestructuradas, empresas colectivas reestructuradas y empresas otrora privadas que desean continuar desarrollándose. En estas condiciones, el control y la gestión de los recursos son más importantes que la propiedad. ${ }^{57}$

El segundo motivo por el que no se debe describir el cambio hablando de privatización, es que esto sugeriría que el Estado ha dejado de dirigir la economía. Aunque resulta evidente que dirigir las empresas ya no es responsabilidad de ningún ministerio, el Estado conserva un papel en la dirección de la economía que va mucho más allá del control macroeconómico ejercido por Estados-nación que actúan como reguladores. En el caso de la RPC, aún existe un gran sector industrial estatal. Las cifras no están claras, pero existen unas 155 empresas dirigidas por el gobierno central, y unas 143,000 sometidas a distintos niveles de jurisdicción. Las empresas estatales pueden estar divididas en participaciones, pero no es necesario. Las que pertenecen a sectores considerados estratégicos (transporte, energía, minería, fármacos, finanzas) no pueden quebrar. ${ }^{58}$ Más aún, el Estado conserva su papel en la planificación económica estratégica, entre otros aspectos, controlando y modificando el equilibrio entre lo público y lo privado en una economía mixta. El Estado garantiza y dirige la competencia en un alto grado.

57. David S. G. Goodman, "Why China has no new middle class: Cadres, managers and entrepreneurs", en David S. G. Goodman (ed.), The New Rich in China: Future Rulers, Present Lives. Londres: Routledge, 2008, p. 29.

58. Jonathan R. Woetzel, "Re-assessing China's state-owned enterprises", The McKinsey Quarterly, julio 2008. 
Es evidente que el principio de santidad de las fuerzas del mercado se ha introducido en el sector público, además de en la empresa privada, claro está. Las empresas estatales tienen que operar dentro del mercado y, como ya se ha dicho, la labor de sus responsables se juzga según sus resultados a ese respecto. La competencia y su mantenimiento son parte esencial de la estrategia de desarrollo de la RPC, junto con la mercantilización, esto significa que existe un alto grado de descentralización gubernamental y de autonomía local en la dirección de las empresas, lo que constituye también un indicador significativo de la reciente experiencia de desarrollo de China. En la actualidad, en la RPC un $70 \%$ del gasto público total, cifra nada desdeñable, se gestiona en jurisdicciones subcentrales, ${ }^{59}$ y la labor de los responsables de las empresas se juzga según los resultados, tanto en empresas privadas como en públicas, o en cualquiera de las numerosas variedades de empresas híbridas que combinan lo privado y lo público. ${ }^{60}$

Elemento corolario de esta introducción de las fuerzas del mercado es el crecimiento de la sociedad de consumo y un aumento significativo de las clases medias. Aunque resulta prácticamente inevitable que la atención se centre en la aparición de los superricos en la era reformista de la RPC, el continuo y considerable crecimiento de las clases medias puede tener mucha más importancia a largo plazo para el país. Es obvio que las clases medias ya existían en la RPC: los profesionales y los directivos fueron de vital importancia en el proyecto de modernización del socialismo de Estado. Pero ahora, con el crecimiento de actividades económicas, profesionales y tecnológicas de todo tipo, las clases medias se han desarrollado aún más. La renta real disponible de estas clases medias es cada vez mayor, y ahora la dedican a mejora y compra de viviendas, educación y más opciones relacionadas con el estilo de vida, incluidas las actividades de ocio, actividades y gasto que tanto las clases medias como el Estado-partido consideran creadores de una comunidad de intereses. Las fuentes oficiales calculan que las clases medias (definidas por sus rentas) constituyen en la actualidad aproximadamente $8 \%$ de la población

59. Pierre F. Landry, Decentralized Authoritarianism in China: The Communist Party's Control of Local Elites in the Post-Mao Era. Cambridge University Press, 2008, p. 3.

60. Bruce J. Dickson, Wealth into Power: The Communist Party's Embrace of China's Private Sector. Cambridge University press, 2008, pp. 40 y 41. 
(personas que ganan más de 60,000 yuanes al año), pero consideran que las clases medias llegarán a representar $20 \%$ de la población en $2020{ }^{61}$

\title{
El reto latinoamericano
}

En un artículo publicado recientemente en The Wall Street Journal, un destacado erudito chino pedía al lector que adivinase en qué país

\begin{abstract}
El PIB aumentó un $11 \%$ cada año durante casi 10 años. El Estado autoritario de partido único fomentó una rápida industrialización trasladando trabajadores a zonas urbanas costeras. El gobierno recibió con los brazos abiertos la inversión extranjera directa y cortejó a las empresas con exenciones fiscales y otros beneficios. El 75\% de los activos de las 100 empresas nacionales más importantes pertenecía al sector estatal. La tasa de ahorro del gobierno se duplicó en menos de una década, mientras el porcentaje de empleo agrícola se redujo más de una tercera parte durante el mismo periodo. ${ }^{62}$
\end{abstract}

A pesar del obvio paralelismo con la China contemporánea, la descripción corresponde a Brasil durante la dictadura militar, de 1965 a 1974. Un útil cañonazo de advertencia para quienes se lancen a describir el modelo chino. Resulta evidente el peligro del triunfalismo o, como lleva mucho tiempo demostrando el ejemplo de Latinoamérica, de suponer que los modelos de desarrollo se trasplantan fácilmente.

La aplicabilidad en Latinoamérica de lo aprendido de la experiencia de desarrollo china durante las tres últimas décadas es un asunto que, obviamente, debe investigarse con mayor profundidad. Resulta evidente que no es posible adoptar todo el paquete: ningún país latinoamericano lleva los últimos 30 años viviendo el socialismo de Estado y el poder de un partido comunista. Incluso las recetas para conseguir mejoras concretas que podrían extraerse de la reciente experiencia china (por ejemplo el desarrollo de una clase media de peso, una inversión considerable en infraestructuras, la dirección estatal de una economía mixta) tienen pocas posibilidades de encontrar demasiado terreno fértil en las culturas políticas y los entornos socioeconómicos locales.

61. David S. G. Goodman (ed.), The New Rich in China: Future Rulers, Present Lives. Londres: Routledge, 2008.

62. Yasheng Huang, "Chinomics: The Fallacy of the Beijing Consensus", The Wall Street Journal, 20 de junio de 2010. 
Por otra parte, salta a la vista el atractivo de la idea del modelo chino para muchos países de Latinoamérica. China ha mantenido un gobierno estable y se ha convertido en una potencia económica internacional cuatro décadas después de ser prácticamente un Estado paria. Su voz también es ahora más independiente en las cuestiones internacionales, independiente sobre todo de Estados Unidos. En el proceso, además, ha aprovechado el discurso dominante de nacionalismo moderno: se ha producido un cambio cultural diseñado para recuperar su lugar en el mundo. ${ }^{63}$ La prueba de este atractivo puede verse en el caso de México: prácticamente en guerra comercial con la RPC durante gran parte de la última década, su relación política es estrechísima en foros internacionales como las Naciones Unidas. ${ }^{64}$ m

63. Véase, por ejemplo, la opinión del embajador brasileño en la RPC, Luiz Augusto de Castro Neves, "Zhongguo de chuqi: Baxi (huo Lading Meizhou) guanjiao" ["El ascenso de China visto desde una perspectiva brasileña (y quizá latinoamericana)"], Lading Meizhou Yanjiu [Revista de estudios latinoamericanos], vol. 29, núm. 2, abril 2007, p. 9.

64. Beatriz Carrillo, Minglu Chen y David S. G. Goodman, "Beyond Asymmetry: Cooperation, conflict and globalisation in Mexico-China relations", The Pacific Review (de próxima aparición). 